\title{
The Importance of Correctly Labelling Ultrasound Images
}

\author{
Duncan L Hamilton ${ }^{1,2 *}$ \\ ${ }^{1}$ Consultant in Anaesthesia \& Acute Pain Medicine, James Cook University Hospital, Middlesbrough, \\ TS4 3BW, UK., ${ }^{2}$ University of Sunderland School of Medicine, Sunderland, SR1 3SD, UK
}

In a recent article in this journal Saad et $\mathrm{al}^{1}$ described the combined use of interscalene and supraclavicular brachial plexus block for brachioaxillary graft in patients with chronic renal failure. The article included a figure showing the ultrasonic appearance seen during supraclavicular brachial plexus block (Figure 1A). I wish to draw attention to the incorrect labelling of the pleura in that image. The pleura is an important structure to identify and avoid with the needle when performing a supraclavicular block and a clear understanding of the relevant ultrasound anatomy is vital.

Figure 1A. The original image from Saad et $\mathrm{al}^{1}$ The structure labelled $\mathrm{p}$ (pleura) is the first rib. Figure 1B. The first rib is outlined in green. A featureless hypoechoic acoustic shadow is seen deep to the hyperechoic shadow generated by the first rib. The pleura (yellow lines) also generates a hyperechoic shadow medial and lateral the first rib (red arrows), however, a grainy shadow generated by the lung is seen deep to it (not clearly seen on this image as it is cropped).

In addition, the point known colloquially as the 'corner pocket' by regional anaesthetists is further medial than marked in the Figure 1A by Saad et al. ${ }^{1}$ The corner pocket (yellow asterix in Figure 1B) is the point where the subclavian artery meets the first rib, and is an important target for the block needle. Failure to adequately advance the needle into the corner pocket can result in block failure, in particular failure to

*Correspondence: Duncan L Hamilton

E mail: duncanleehamilton@nhs.net

https://orcid.org/0000-0003-2132-4867

Received: 08/08/2020

Accepted: 04/04/2021

DOI: http:/doi.org/10.4038/slja.v29i1.8657

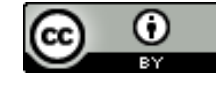

block the territory supplied by the lower trunk of the brachial plexus. ${ }^{2}$

\section{Reference}

1. Saad HA, Hashish MA, Diab DG, Abdel Ghaffar NA. Combined interscalene and supraclavicular brachial plexus block using ultrasound guidance versus general anaesthesia for brachioaxillary graft in patients with chronic renal failure. Sri Lankan Journal of Anaesthesiology. 2020; 28 (2): 74-9. http://doi.org/10.4038/slja.v28i2.8501

2. Macfarlane A, Brull R. Ultrasound guided supraclavicular block. The journal of New York school of regional anesthesia. 2009; 12: 6-10

\section{Conflict of Interest: None}

Financial support: None

Figures: $1 \mathrm{~A}$ and $1 \mathrm{~B}$

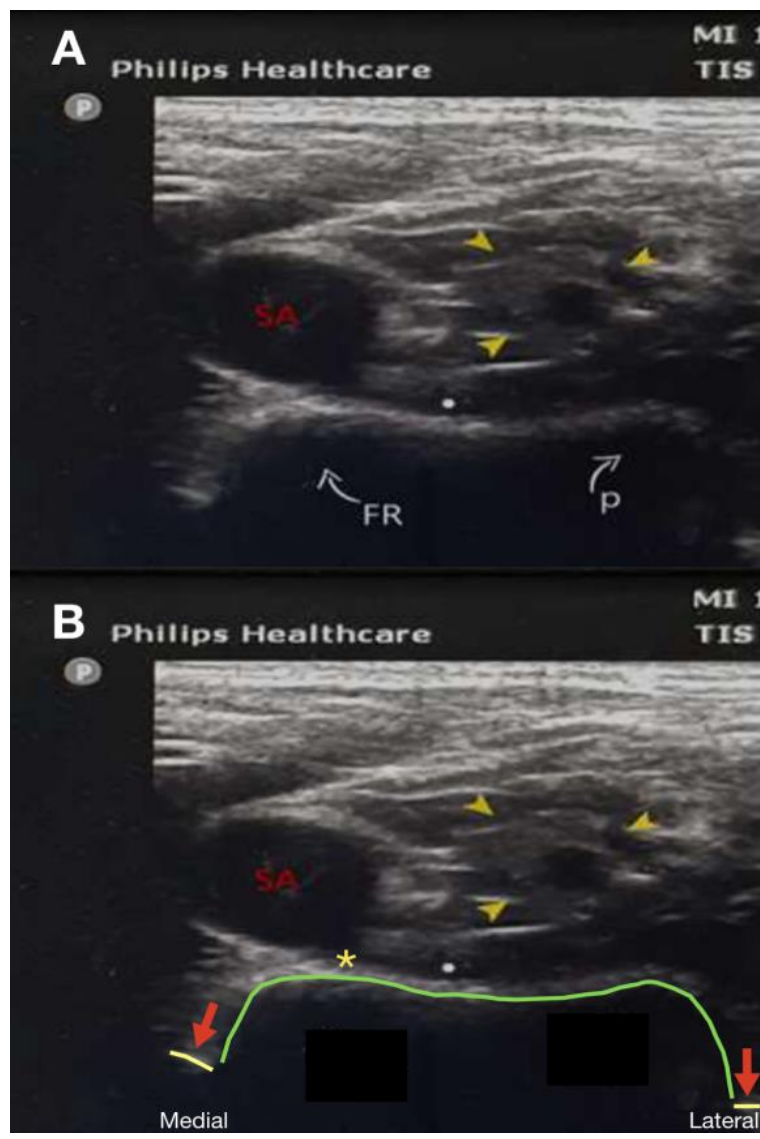

